\title{
Gimbal-Less MEMS Two-Axis Optical Scanner Array With High Fill-Factor
}

\author{
Jui-che Tsai and Ming C. Wu, Fellow, IEEE
}

\begin{abstract}
In this paper, we report on a MEMS-based two-axis optical scanner array with a high fill factor $(>96 \%)$, large mechanical scan angles $\left( \pm 4.4^{\circ}\right.$ and $\left.\pm 3.4^{\circ}\right)$, and high resonant frequencies $(20.7 \mathrm{kHz})$. The devices are fabricated using SUMMiT-V, a five-layer surface-micromachining process. High fill factor, which is important for $1 \times \mathrm{N}^{2}$ wavelength-selective switches (WSSs), is achieved by employing crossbar torsion springs underneath the mirror, eliminating the need for gimbal structures. The proposed mirror structure can be readily extended to two-dimensional (2-D) array for adaptive optics applications. In addition to two-axis rotation, piston motion with a stroke of $0.8 \mu \mathrm{m}$ is also achieved.
\end{abstract}

[1496]

Index Terms-Microelectromechanical devices, micromirror array, optical components, optical fiber switches, wavelength division multiplexing (WDM), wavelength-selective switches.

\section{INTRODUCTION}

M ICROELECTROMECHANICAL systems (MEMS)based optical scanners have attracted a great deal of attention. In telecommunications, they are the key enabling components for two-dimensional (2-D) [1], [2] and three-dimensional (3-D) [3] optical crossconnects (OXC), dynamic gain equalizers [4], wavelength add-drop multiplexers (WADM) [5], and wavelength-selective switches (WSS) [6]-[19]. They offer low optical insertion loss and crosstalk, independence of polarization and wavelength, as well as optical transparency for bit rate and data format. In adaptive optics, tip-tilt-piston micromirror arrays [20] and deformable mirrors [21], [22] compensate wavefront distortions introduced by the medium and help achieve sharper images approaching diffraction limit. MEMS optical scanners are also widely used in display [23], endoscopic imaging, and confocal microscopy [24], [25].

A two-axis micromirror array is the key enabling element for $1 \times \mathrm{N}^{2}$ WSS. Most of the previously reported WSSs employ one-dimensional (1D) array of fiber collimators, hence referred to as $1 \times \mathrm{N}$ WSS [6]-[11]. The maximum port count is limited by optical diffraction. The $1 \times \mathrm{N}^{2}$ WSS increases the port count from $\mathrm{N}$ to $\mathrm{N}^{2}$ by using a 2-D collimator array. Though $1 \times \mathrm{N}^{2}$ WSS has been achieved by cascaded one-axis scanners

Manuscript received January 4, 2005; revised May 17, 2005. This work was supported by DARPA/SPAWAR under Contract N66001-00-C-8088. Subject Editor H. Zappe.

J.-C. Tsai is with the Graduate Institute of Electro-Optical Engineering, National Taiwan University, Taiwan (e-mail: jctsai@icsl.ucla.edu).

M. C. Wu was with the Department of Electrical Engineering, University of California, Los Angeles, CA 90095 USA. He is now with the University of California, Berkeley, Department of Electrical Engineering and Computer Sciences and Berkeley Sensor and Actuator Center (BSAC), Berkeley, CA 94720-1774 USA.

Digital Object Identifier 10.1109/JMEMS.2005.859193

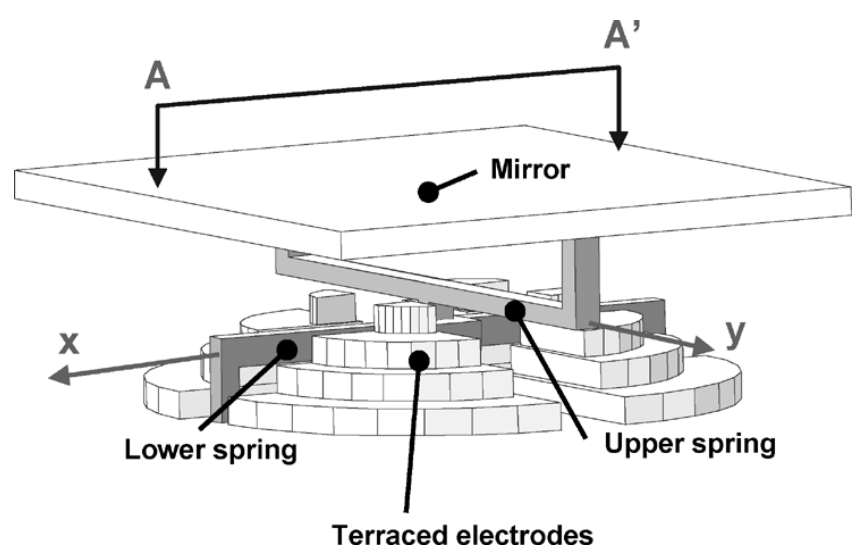

Fig. 1. Schematic of the two-axis analog micromirror with terraced electrodes and hidden crossbar torsion springs.

[12]-[14], the use of two-axis micromirror array would eliminate the need of 4- $f$ optics and greatly simplify the system as well as improve its performance [15]-[19].

Gimbaled structures have been widely used in two-axis MEMS scanners [26]. However, the gimbals occupy large areas and sacrifice the fill factor of the mirrors. Previously, an electroplated two-axis scanner with a crossbar torsion spring was reported for 3-D OXC applications [27]. The mirror size was relatively large $(570 \mu \mathrm{m})$, and the actuation voltage was high ( $244 \mathrm{~V}$ for $2.65^{\circ}$ rotation). The potential for high fill factor has not been demonstrated. Recently, we have reported the first high fill-factor array of two-axis scanners for $1 \times \mathrm{N}^{2}$ WSS applications [15]. They are made by a five-layer polysilicon surface-micromachining process (SUMMiT-V). The small mirror size (100 to $200 \mu \mathrm{m}$ ) meets the requirement of WSS. Terraced electrodes [28] were employed to reduce the actuation voltage. In this paper, we present the detailed design, fabrication, and measurement of the two-axis analog micromirror array. High fill factors (96\%) and large mechanical scan angles $\left( \pm 4.4^{\circ}\right.$ and $\pm 3.4^{\circ}$ ) have been achieved. In addition to two-axis rotation, piston motion can also be attained by biasing all electrodes together. Two-dimensional arrays of such tip-tilt-piston micromirrors are useful for adaptive optics applications.

\section{Device Design AND Modeling}

Fig. 1 shows the schematic of the two-axis micromirror. Crossbar torsion springs underneath the mirror are employed to achieve high fill factor. Four circular terraced electrodes are employed to reduce the actuation voltage. The structure in Fig. 1 can be considered as a multilevel parallel-plate-actuated scanner and the model derived in [29] can therefore be modified for analyzing our device by superimposing the effects of 


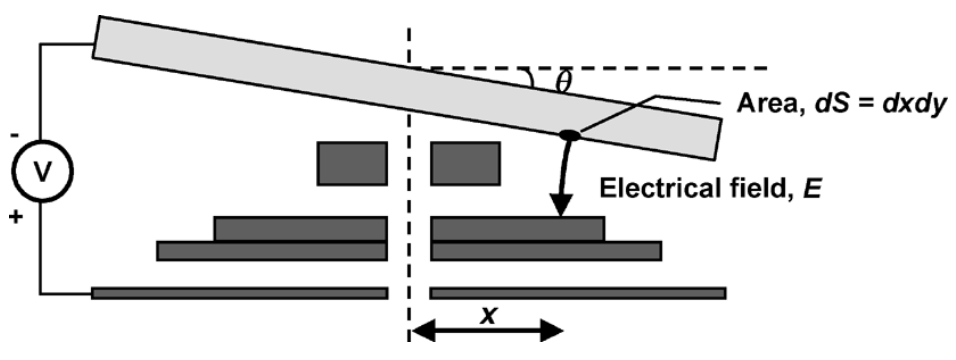

Fig. 2. Analysis of the terraced-electrode scanner.

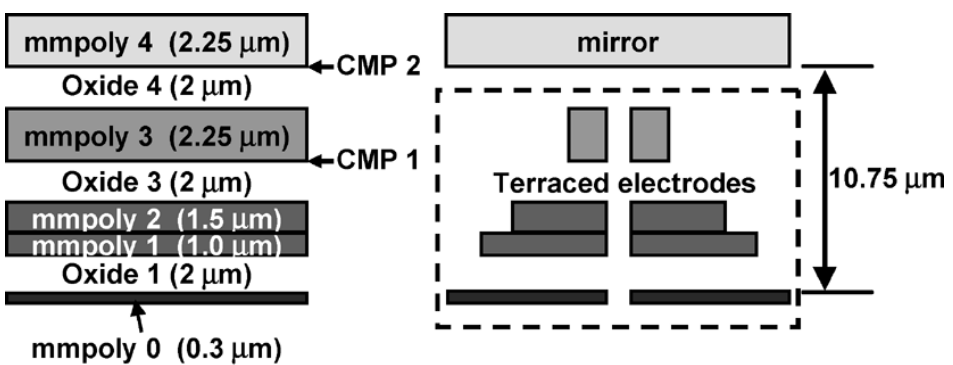

(a)

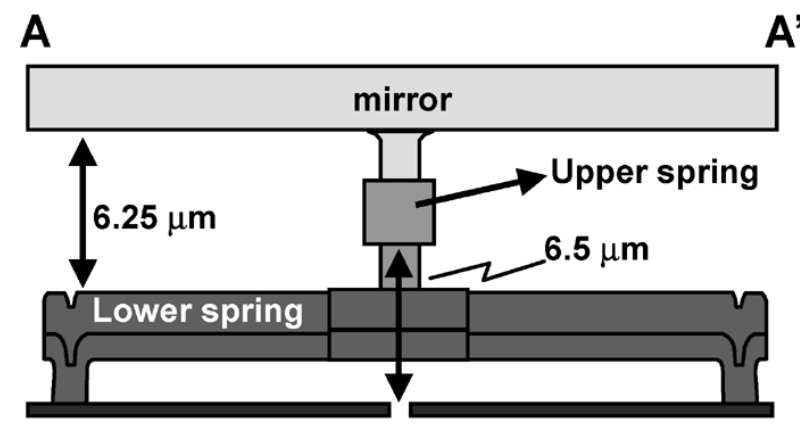

(b)

Fig. 3. (a) Cross section of the two-axis analog micromirror and the corresponding polysilicon layers in SUMMiT-V process, and (b) cross section of the mirror and the crossbar springs. (The electrodes are not shown in this figure.)

different electrode layers. Referring to Fig. 2, the electrical torque generated by the applied voltage can be expressed as

$$
T_{\text {elec }}(V, \theta, z)=\sum_{i} \int_{A_{i}} \frac{1}{2} \varepsilon_{0} E_{i}(V, \theta, z, x, y)^{2} \cdot x \cdot d x d y
$$

where $\boldsymbol{V}, \boldsymbol{\theta}$, and $\boldsymbol{z}$ are the applied voltage, scanner rotation angle, and downward sagging, respectively. The summation index $i$ refers to the level of electrodes, and $A_{i}$ is the area of the $i$-th electrode. $(\mathbf{1} / \mathbf{2}) \varepsilon_{0} \boldsymbol{E}_{\boldsymbol{i}}^{\mathbf{2}}$ is the electrical force density. The electrical downward pulling force is

$$
F_{\text {elec }}(V, \theta, z)=\sum_{i} \int_{A_{i}} \frac{1}{2} \varepsilon_{0} E_{i}(V, \theta, z, x, y)^{2} \cdot d x d y
$$

which contributes to the sagging of the mirror, $z$.

The restoring mechanical torque of the torsion spring is $\boldsymbol{T}_{\text {mech }}(\boldsymbol{\theta})=\boldsymbol{k}_{\boldsymbol{t}} \cdot \boldsymbol{\theta}$ whereas the upward restoring force due to spring bending is $\boldsymbol{F}_{\text {mech }}(\boldsymbol{z})=\boldsymbol{k}_{\boldsymbol{z}} \cdot \boldsymbol{z} \cdot \boldsymbol{k}_{\boldsymbol{t}}$ and $\boldsymbol{k}_{\boldsymbol{z}}$ are the torsion spring constant and bending spring constant, respectively. In equilibrium, $\boldsymbol{T}_{\text {elec }}=\boldsymbol{T}_{\text {mech }}$ and $\boldsymbol{F}_{\text {elec }}=\boldsymbol{F}_{\text {mech }}$. Therefore, for a given voltage, the rotation angle and sagging can be found by solving the above equations.
Using this analysis, we found that in the case of square electrodes, the terraced structure reduces the actuation voltage by $34 \%$, compared with a standard parallel plate scanner. In the case of circular electrodes, the voltage is reduced by $25 \%$. The calculated transfer characteristics of the scanners will be presented later, together with the experimental results.

\section{FABRICATION AND TESTING}

The devices are fabricated using the SUMMiT-V surface-micromachining process provided by Sandia National Laboratory [30]. It has five polysilicon layers, including one nonreleasable ground layer (mmpoly0) and four structural layers (mmpoly1 to mmpoly4). Fig. 3(a) shows the cross section of the two-axis analog micromirror and the corresponding polysilicon layers. The terraced electrodes are made of the bottom four polysilicon layers (mmpoly0 to mmpoly3), whereas the top polysilicon layer (mmpoly4) is used for the mirror. The chemical-mechanical-planarization (CMP) process before the deposition of the top two polysilicon layers eliminates the topography underneath the mirrors. They also provides a large gap spacing $(10.75 \mu \mathrm{m})$ between the mirror and substrate, increasing the maximum rotation angle that can be achieved by the surface-micromachining process. Fig. 3(b) shows the cross section of the mirror and the 


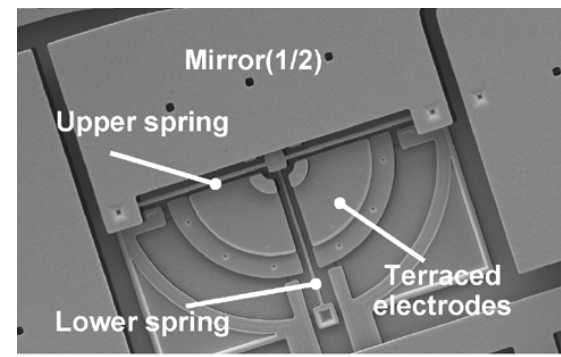

(a)

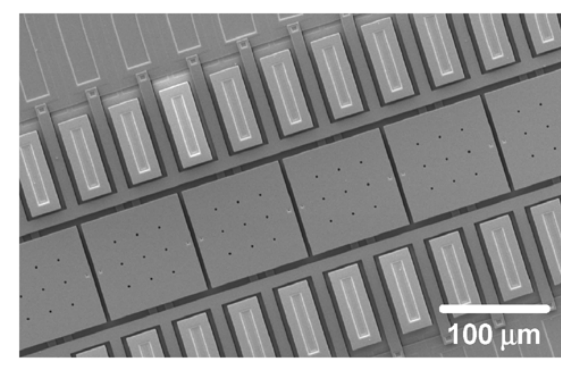

(b)

Fig. 4. SEM of (a) two-axis micromirror with the lower half of the mirror intentionally removed and (b) $1 \times 10$ array of two-axis micromirrors.

springs (along A-A' in Fig. 1). For clarity, the terrace electrodes are not shown in this drawing. The crossbar torsion springs consist of two parts. For our nominal design, the lower spring (rotation about $\mathrm{x}$ axis) is made of stacked mmpoly $1 / \mathrm{mmpoly} 2$ layers, while the upper spring (rotation about y axis) is made of mmpoly3 layer. This unique multilayer design enables us to achieve large clearance for both rotation axes: $6.5 \mu \mathrm{m}$ and $6.25 \mu \mathrm{m}$ for rotation about the lower ( $\mathrm{x}$ axis) and upper (y axis) springs, respectively.

Fig. 4(a) shows the scanning electron micrographs (SEM) of the two-axis micromirror. The lower half of the mirror is removed to reveal the underlying structures. The SEM of the array is shown in Fig. 4(b). A high fill-factor of $96 \%$ is achieved (96 $\mu \mathrm{m}$ mirror on $100 \mu \mathrm{m}$ pitch). The fill factor can be further increased by reducing the gap between mirrors (minimum gap of 1 $\mu \mathrm{m}$ allowed by the design rules). The array size is $1 \times 10$, limited by the chip size $\left(3 \times 6 \mathrm{~mm}^{2}\right)$ of the multi-user runs. The radius of curvature of the mirror is $50 \mathrm{~mm}$ before metallization. After high-reflection coating with metal films (Cr/Au: $5 \mathrm{~nm} / 200$ $\mathrm{nm}$ ), it is reduced to $32 \mathrm{~mm}$ due to residue stress.

Fig. 5 shows the dc scanning characteristics. The dots are measured data while the solid lines are obtained by theoretical simulation discussed previously. The maximum angles of the theoretical curves are limited by the pull-in effect. Measured scan angles of $\pm 4.4^{\circ}$ (at $90 \mathrm{~V}$ ) and $\pm 3.4^{\circ}$ (at $91.5 \mathrm{~V}$ ) are achieved. The experimental data agree very well with the theoretical calculations. The difference in the actuation voltages for the two axes is due to the unequal spring constants for the lower and upper springs. The maximum rotation angle about the $y$ axis is slightly smaller in both the experiment and simulation. This is due to a smaller $\boldsymbol{k}_{z} / \boldsymbol{k}_{\boldsymbol{t}}$ ratio (to be discussed in Section IV). By applying the same voltage on the four electrodes simultaneously, pure piston motion of $0.3 \mu \mathrm{m}$ can be achieved at $80 \mathrm{~V}$. The mirror and the springs are grounded during actuation, whereas the

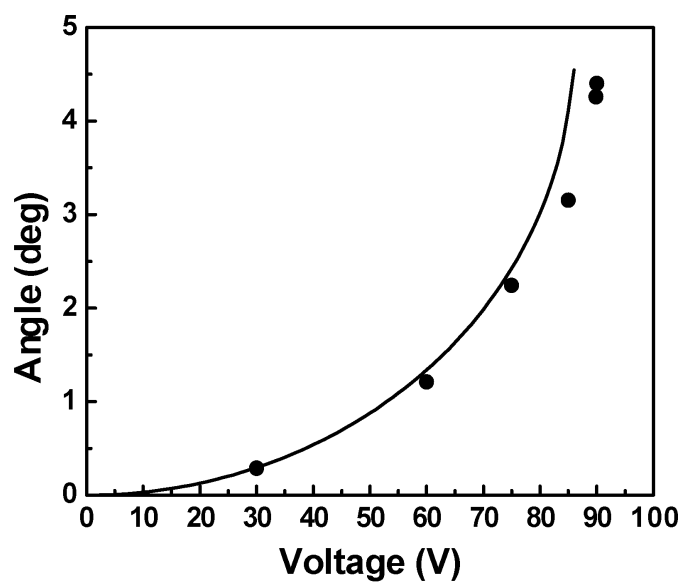

(a)

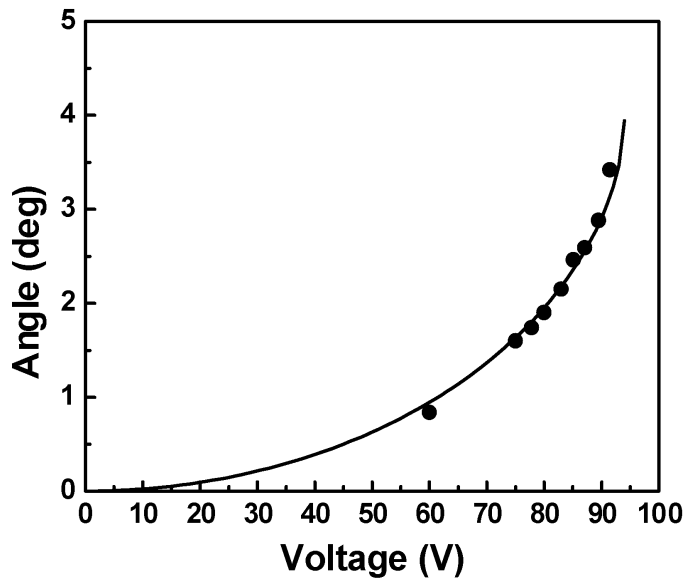

(b)

Fig. 5. DC characteristics of the two-axis micromirror: (a) $\pm 4.4^{\circ}$ at $90 \mathrm{~V}$ about $\mathrm{x}$ axis; (b) $\pm 3.4^{\circ}$ at $91.5 \mathrm{~V}$ about $\mathrm{y}$ axis are achieved.

electrodes are biased at the desired voltage. An extended ground plane and overhanging polysilicon structures are deployed underneath the mirror to shield the mirror from the bottom insulating dielectric. This minimizes the dielectric charging effect and improves the mirror stability. We have measured the angular drift of the mirror under dc bias conditions. The drift is found to be $<0.03^{\circ}$ over 3 hours in open-loop operation.

Fig. 6 shows the frequency responses of the two-axis scanner for both $\mathrm{x}$ and $\mathrm{y}$ axes. The resonant frequencies before metallization are $20.7 \mathrm{kHz}$ and $24.3 \mathrm{kHz}$, respectively. They are reduced to $13.9 \mathrm{kHz}$ and $16.5 \mathrm{kHz}$ due to the additional metal weight after metallization. The performance of the $1 \times \mathrm{N}^{2} \mathrm{WSS}$ using the twoaxis micromirror array was characterized using our existing WSS test setup. To match the optical system, the mirrors used here have a similar design but a pitch of $200 \mu \mathrm{m}$ and a fill factor of $98 \%$. Their mechanical resonant frequency is $1.4 \mathrm{kHz}$ after metallization. The switching time of the WSS depends on the scanner resonant frequency and the distance between fiber collimators. It is characterized by monitoring the optical power transition of the $1 \times \mathrm{N}^{2}$ WSS during switching. The switching time is less than 2 ms, as shown in Fig. 7. The detailed design and performance of the $1 \times \mathrm{N}^{2}$ WSS will be reported later. The $100-\mu \mathrm{m}$-pitch mirror array can be used if we modify the optical system, for example, using a resolution lens with a smaller $f$-number. 


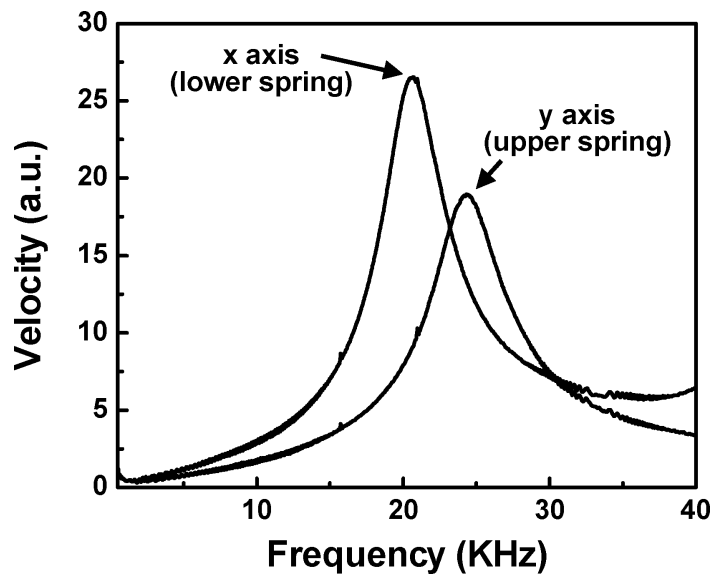

Fig. 6. Frequency responses of the two-axis MEMS mirror for both $\mathrm{x}$ and $\mathrm{y}$ axes. The resonant frequencies before metallization are 20.7 and $24.3 \mathrm{kHz}$, respectively.

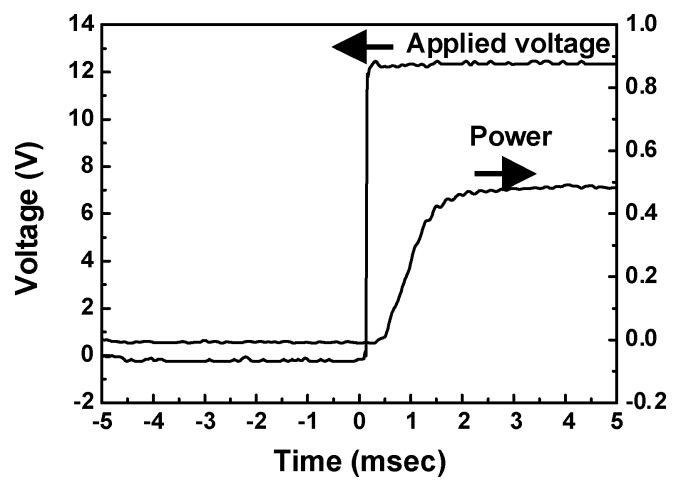

Fig. 7. Temporal response when the optical power is switched to one of the output ports in a $1 \times \mathrm{N}^{2}$ WSS.

\section{DISCUSSION}

\section{A. Spring Designs}

The design of the torsion springs plays a critical role in the performance of our terraced-electrode micromirrors. Due to the small gap spacing $(2 \mu \mathrm{m})$ between the top electrodes and the mirror, the force density around the mirror center is very significant. This exerts a large downward pulling force on the mirror, leading to a piston motion. Depending on the applications, the piston motion may or may not be desirable. In adaptive optics, tip-tilt-piston motion is necessary to correct the phase front distortion [20]. On the other hand, for beamsteering applications such as $1 \times \mathrm{N}^{2}$ WSS, the piston motion reduces the scan angles through the reduction of mirror-electrode gaps. By designing the springs properly, we can either enhance or suppress the up-and-down piston motion.

The torsion spring has a torsion spring constant $\boldsymbol{k}_{\boldsymbol{t}}$, accompanied by an up-and-down bending constant $\boldsymbol{k}_{\boldsymbol{z}}$. The piston motion can be suppressed by increasing the ratio $\boldsymbol{k}_{z} / k_{\boldsymbol{t}} \cdot \boldsymbol{k}_{\boldsymbol{t}}$ can be expressed as

$$
k_{t}=\frac{2 G_{p o l y} w_{n}^{3} t_{n}}{3 l_{n}}\left(1-\frac{192}{\pi^{5}} \frac{w_{n}}{t_{n}} \tanh \left(\frac{\pi}{2} \frac{t_{n}}{w_{n}}\right)\right)
$$

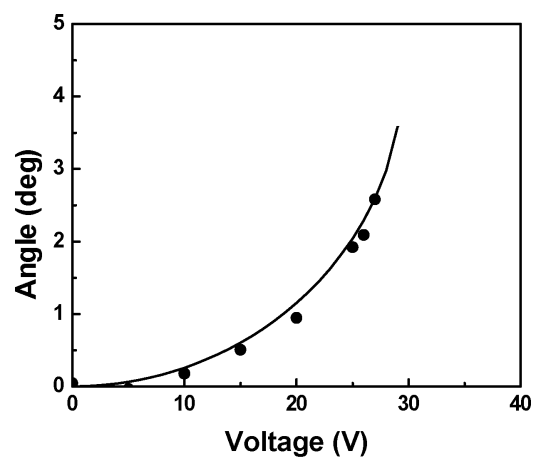

(a)

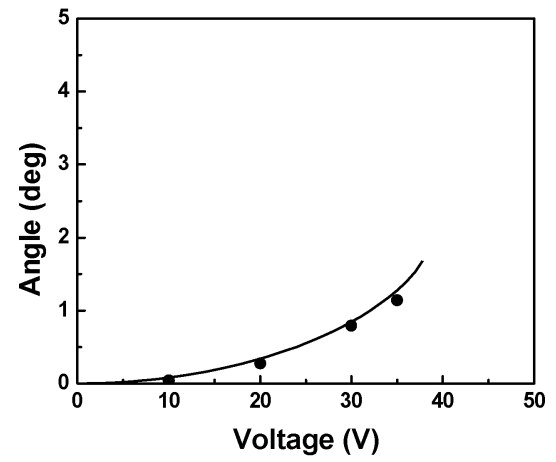

(b)

Fig. 8. DC characteristics of the two-axis micromirror with an alternative spring design: (a) $\pm 2.58^{\circ}$ at $27 \mathrm{~V}$ about $\mathrm{x}$ axis; (b) $\pm 1.14^{\circ}$ at $35 \mathrm{~V}$ about $\mathrm{y}$ axis are achieved.

while $k_{z}$ is

$$
\boldsymbol{k}_{z}=\left(\left(\frac{2 \boldsymbol{E}_{\boldsymbol{p o l y}} \boldsymbol{w}_{\boldsymbol{l}} \boldsymbol{t}_{\boldsymbol{l}}^{3}}{\boldsymbol{l}_{\boldsymbol{l}}^{3}}\right)^{-1}+\left(\frac{2 \boldsymbol{E}_{\boldsymbol{p o l y}} \boldsymbol{w}_{\boldsymbol{u}} \boldsymbol{t}_{\boldsymbol{u}}^{3}}{\boldsymbol{l}_{\boldsymbol{u}}^{3}}\right)^{-1}\right)^{-1}
$$

where $\boldsymbol{w}, \boldsymbol{t}$, and $\boldsymbol{l}$ are the width, thickness, and length of the springs, respectively. The subscript $\boldsymbol{n}$ is either $\boldsymbol{l}$ (denoting the lower spring) or $\boldsymbol{u}$ (denoting the upper springs). $\boldsymbol{G}_{\boldsymbol{p o l y}}$ and $E_{p o l y}$ are the shear modulus and Young's modulus of polysilicon, respectively. In our design, the spring width is fixed at the minimum line width, $1 \mu \mathrm{m}$, limited by SUMMiT design rules. Therefore, the thickness of the spring always has a dimension no smaller than the width. It can be seen that $\boldsymbol{k}_{\boldsymbol{t}}$ has a quasilinear dependence of the thickness while $\boldsymbol{k}_{z}$ has a quasicubic dependence. This means that reducing the spring thickness leads to a reduction of the $\boldsymbol{k}_{z} / \boldsymbol{k}_{\boldsymbol{t}}$ ratio, or larger sagging (piston motion) during actuation.

\section{B. Comparison}

In addition to our nominal design, we have employed an alternative spring design for the terraced-electrode scanners. It uses only mmpoly 1 (instead of mmpoly $1 /$ mmpoly 2 stack) as the lower spring. This reduces the lower spring thickness by 2.5 times. The experimental and simulated results are shown in Fig. 8. Lower actuation voltage is required; however, the maximum angle is also reduced due to increased sagging. The measured scan angles are $\pm 2.58^{\circ}$ (at $27 \mathrm{~V}$ ) and $\pm 1.14^{\circ}$ (at $35 \mathrm{~V}$ ). The theoretical curves match with the measured 
data. The discrepancy of the maximum angle between the experiment and simulation is under investigation. Pure piston motion of $0.8 \mu \mathrm{m}$ has been achieved at $30 \mathrm{~V}$ by applying the same voltage on the four electrodes simultaneously. Compared with our nominal design, this variant has a larger piston motion but a smaller scan angle. It is more suitable for the application in adaptive optics.

\section{CONCLUSION}

We have demonstrated a two-axis analog micromirror array with a high fill-factor $(96 \%)$ and large mechanical scan angles $\left( \pm 4.4^{\circ}\right.$ and $\left.\pm 3.4^{\circ}\right)$. The high fill-factor is achieved by the use of hidden springs. Terraced electrodes are employed to reduce the actuation voltage (by 25 to 34\%). The mechanical resonant frequency is $20.7 \mathrm{kHz}$. Switching time of $<2 \mathrm{~ms}$ has also been achieved in a prototype wavelength-selective switch (WSS) using double sized mirrors $(200 \mu \mathrm{m})$ with a lower resonant frequency $(1.4 \mathrm{kHz})$. In the design with more compliant springs, a large piston motion of $0.8 \mu \mathrm{m}$ is achieved, which is suitable for adaptive optics applications.

\section{ACKNOWLEDGMENT}

The authors would like to thank S. Huang, D. Hah, M.-C. Lee, and C.-H. Chi, and W. Piyawattanametha of UCLA for the SEM images and technical assistance.

\section{REFERENCES}

[1] L. Y. Lin, E. L. Goldstein, and R. W. Tkach, "Free-space micromachined optical switches for optical networking," IEEE J. Sel. Topics Quantum Electron.: Special Issue on Microoptoelectro-Mechanical Systems (MOEMS), vol. 5, pp. 4-9, 1999.

[2] A. Husain, "MEMS-based photonic switching in communications networks," in Proc. Optical Fiber Communication, Anaheim, CA, 2001, WX1.

[3] R. Ryf et al., "1296-port MEMS transparent optical crossconnect with 2.07 Petabit/s switch capacity," in Proc. Optical Fiber Communication, Anaheim, CA, 2001, postdeadline paper, PD28.

[4] D. T. Neilson et al., "High-dynamic range channelized MEMS equalizing filter," in Proc. Optical Fiber Communication, Anaheim, CA, 2002, ThCC3, pp. 586-588.

[5] J. E. Ford, V. A. Aksyuk, D. J. Bishop, and J. A. Walker, "Wavelength add-drop switching using tilting micromirrors," J. Lightw. Technol., vol. 17, pp. 904-911, 1999.

[6] D. M. Marom et al., "Wavelength-selective $1 \times 4$ switch for $128 \mathrm{WDM}$ channels at $50 \mathrm{GHz}$ spacing," in Proc. Optical Fiber Communication, Anaheim, CA, 2002, postdeadline paper, FB7.

[7] S. Huang, J. C. Tsai, D. Hah, H. Toshiyoshi, and M. C. Wu, "Open-loop operation of MEMS WDM routers with analog micromirror array," in Proc. 2002 IEEE/LEOS Optical MEMS Confe, Lugano, Switzerland, 2002, pp. 179-180.

[8] T. Ducellier et al., "The MWS $1 \times 4$ : A high performance wavelength switching building block," in Proc. Eur. Conf. Optical Communication, Coppenhagen, Denmark, 2002, Session 2.3.1.

[9] D. M. Marom et al., "Wavelength selective $4 \times 1$ switch with high spectral efficiency, $10 \mathrm{~dB}$ dynamic equalization range and internal blocking capability," in Proc. Eur. Conf. Optical Communication, Rimini, Italy, 2003, Mo3.5.3.

[10] — " "64 channel $4 \times 4$ wavelength-selective cross-connect for $40 \mathrm{~Gb} / \mathrm{s}$ channel rates with $10 \mathrm{~Tb} / \mathrm{s}$ throughput capacity," in Proc. Eur. Conf. Optical Communication, Rimini, Italy, 2003, We4.P.130.
[11] J. C. Tsai, S. Huang, D. Hah, H. Toshiyoshi, and M. C. Wu, "Openloop operation of MEMS-based $1 \times \mathrm{N}$ wavelength-selective switch with long-term stability and repeatability," IEEE Photon. Technol. Lett., vol. 16, pp. 1041-1043, Apr. 2004.

[12] J. C. Tsai, S. Huang, D. Hah, and M. C. Wu, "Wavelength-selective $1 \times \mathrm{N}^{2}$ switches with two-dimensional input/output fiber arrays," in Proc. Conf. Lasers and Electro-Optics, Baltimore, MD, 2003, CTuQ4.

[13] _ "Analog micromirror arrays with orthogonal scanning directions for wavelength-selective $1 \times \mathrm{N}^{2}$ switches," in Proc. Transducers'03, Boston, MA, 2003, pp. 1776-1779.

[14] — , " $1 \times \mathrm{N}^{2}$ wavelength-selective switch with telescope-magnified 2D input/output fiber collimator array," in Proc. 2003 IEEE/LEOS Optical MEMS Conf., Waikoloa, HI, 2003, pp. 45-46.

[15] J. C. Tsai, S. Huang, and M. C. Wu, "High fill-factor two-axis analog micromirror array for $1 \times \mathrm{N}^{2}$ wavelength-selective switches," in Proc. MEMS, Maastricht, The Netherlands, 2004, pp. 101-104.

[16] J. C. Tsai and M. C. Wu, " $1 \times \mathrm{N}^{2}$ wavelength-selective switches with high fill-factor two-axis analog micromirror arrays," in Proc. Optical Fiber Communication, Los Angeles, CA, 2004, MF42.

[17] J. C. Tsai, S. Huang, D. Hah, and M. C. Wu, " $1 \times \mathrm{N}^{2}$ wavelength-selective switches with tilted 2D collimator arrays for inter-channel-response suppression," in Proc. Conf. Lasers and Electro-Optics, San Francisco, CA, 2004, CTuFF7.

[18] J. C. Tsai, L. Fan, D. Hah, and M. C. Wu, "A high fill-factor, large scan-angle, two-axis analog micromirror array driven by leverage mechanism," in Proc. 2004 IEEE/LEOS Optical MEMS Conf., Takamatsu, Japan, 2004, pp. 30-31.

[19] J. C. Tsai, L. Fan, C. H. Chi, D. Hah, and M. C. Wu, "A large port-count $1 \times 32$ wavelength-selective switch using a large scan-angle, high fillfactor, two-axis analog micromirror array," in Proc. Eur. Conf. Optical Communication, Stockholm, Sweden, 2004, Tu1.5.2.

[20] M. A. Helmbrecht, U. Srinivasan, C. Rembe, R. T. Howe, and R. S. Muller, "Micromirrors for adaptive-optics arrays," in Proc. Transducers'01, Munich, Germany, 2001, pp. 1290-1293.

[21] J. A. Perreault and T. G. Bifano, "High-resolution wavefront control using micromirror arrays," in Proc. Solid-State Sensor, Actuator and Microsystems Workshop, Hilton Head Island, SC, Jun. 6-10, 2004, pp. 83-86.

[22] Y. Hishinuma and E. H. Yang, "Single-crystal silicon continuous membrane deformable mirror with PZT unimorph microactuator arrays," in Proc. Solid-State Sensor, Actuator and Microsystems Workshop, Hilton Head Island, SC, Jun. 6-10, 2004, pp. 87-90.

[23] L. J. Hornbeck, "Digital light processing for high brightness, high resolution applications," in Proc. SPIE Electronic Imaging EI'97, Projection Displays III, vol. 3013, San Jose, CA, Feb. 10-12, 1997.

[24] K. Murakami, A. Murata, T. Suga, H. Kitagawa, Y. Kamiya, M. Kubo, K. Matsumoto, H. Miyajima, and M. Katashiro, "A miniature confocal optical microscope with MEMS gimbal scanner," in Proc. Transducers'03, Boston, MA, 2003, pp. 587-590.

[25] W. Piyawattanametha, L. Fan, S. Hsu, M. Fujino, M. C. Wu, P. R. Herz, A. D. Aguirre, Y. Chen, and J. G. Fujimoto, "Two-dimensional endoscopic MEMS scanner for high resolution optical coherence tomography," in Proc. CLEO, San Francisco, CA, 2004, CWS2.

[26] M. Whitley, J. A. Hammer, Z. Hao, B. Wingfield, and L. Nelson, "A single two-axis micromachined tilt mirror and linear array," Proc. SPIE, vol. 4985, pp. 83-94, 2003.

[27] J. H. Kim, H. K. Lee, B. I. Kim, J. W. Jeon, J. B. Yoon, and E. Yoon, "A high fill-factor micro-mirror stacked on a crossbar torsion spring for electrostatically-actuated two-axis operation in large-scale optical switch," in Proc. MEMS, Kyoto, Japan, 2003, pp. 259-262.

[28] R. Sawada, J. Yamaguchi, E. Higurashi, A. Shimizu, T. Yamamoto, N Takeuchi, and Y. Uenishi, "Single Si crystal 1024ch MEMS mirror based on terraced electrodes and a high-aspect ratio torsion spring for 3-D cross-connect switch," in Proc. 2002 IEEE/LEOS Optical MEMS Conf., Lugano, Switzerland, 2002, pp. 11-12.

[29] H. Toshiyoshi, W. Piyawattanametha, C. T. Chan, and M. C. Wu, "Linearization of electrostatically actuated surface micromachined 2-D optical scanner," J Microelectromech. Syst., vol. 10, no. 2, pp. 205-214, Jun. 2001.

[30] . [Online]. Available: http://www.sandia.gov/mstc/technologies/micromachines/tech-info/technologies/summit5.html 


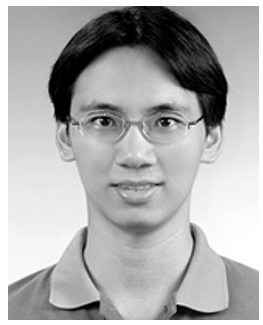

Jui-che Tsai received the B.S. degree in electrical engineering from National Taiwan University (NTU), Taiwan, in 1997. He entered the Graduate Institute of Electro-Optical Engineering at NTU after completing his undergraduate study, and received the M.S. degree in electro-optical engineering in 1999. Between 1999 and 2001, he served in the military as a second lieutenant. He received the Ph.D. degree in electrical engineering from University of California, Los Angeles (UCLA), in 2005.

He is now an Assistant Professor with the Graduate Institute of Electro-Optical Engineering, National Taiwan University, Taiwan. His research interests include optical MEMS, optical fiber communication, and biophotonics.

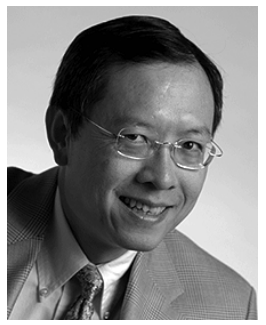

Ming C. Wu (S'82-M'83-SM'00-F'02) received the B.S. degree from National Taiwan University, (NTU), Taiwan, and the M.S. and Ph.D. degrees from University of California at Berkeley (UC Berkeley), in 1983, 1985, and 1988, respectively, all in electrical engineering.

$\mathrm{He}$ is Professor of Electrical Engineering and Computer Sciences at the University of California, Berkeley, and Co-Director of Berkeley Sensors and Actuators Center (BSAC). His research interests include optical MEMS (micro-electro-mechanical systems), optoelectronics, and biophotonics. Before joining the faculty of UC Berkeley, he was a Member of Technical Staff at AT\&T Bell Laboratories, Murray Hill, NJ, from 1988 to 1992, and Professor of Electrical Engineering at the University of California at Los Angeles (UCLA) from 1993 to 2004. $\mathrm{He}$ also held the position of Director of Nanoelectronics Research Facility and Vice Chair for Industrial Relations during his tenure at UCLA. In 1997, he co-founded OMM, San Diego, CA, to commercialize MEMS optical switches. He has published over 400 papers, contributed five book chapters, and holds 11 U.S. patents.

Dr. Wu is a David and Lucile Packard Foundation Fellow (1992-1997). He was the founding Co-Chair of IEEE LEOS Summer Topical Meeting on Optical MEMS (1996), the predecessor of IEEE/LEOS International Conference on Optical MEMS. He has also served in the program committees of many technical conferences, including MEMS, OFC, CLEO, LEOS, MWP, IEDM, DRC, ISSCC; and as Guest Editor of two special issues of IEEE journals on Optical MEMS. 